\title{
Nietzsche belle époque: decadência e performatividade
}

\author{
Fabiano Lemos*
}

\begin{abstract}
Resumo: A apropriação de Nietzsche em torno do termo décadence - $\mathrm{e}$ seus conexos - nos textos redigidos entre 1887 e 1888 pode nos mostrar não apenas seu interesse de por um léxico típico da literatura e da fisiologia da belle époque, mas o modo como o uso desse vocabulário lhe permitiu, ao mesmo tempo, se colocar diante de seu tempo e estabelecer novas estratégias de escrita. Partindo, portanto, do horizonte decadentista e de seus procedimentos narrativos, entre 1871 e 1914, o artigo pretende analisar os tensionamentos envolvidos na inscrição de Nietzsche no período que se estende de seus últimos escritos até sua primeira recepção. Palavras-chave: Nietzsche - decadência - belle époque
\end{abstract}

"J'ai cultivé mon hysterie avec jouissance et terreur".

Charles Baudelaire, Journaux intimes.

\section{Posição do problema: Nietzsche como autor do fin-de-siècle}

Exaurido, o duque Jean Floressas des Esseintes se deixa cair sobre uma cadeira, convencido de que todo lugar ao qual ele se dirigisse haveria de trazer consigo apenas renovadas desilusões. Des Esseintes havia aprendido, aliás, que essa era não apenas uma

* Professor do Departamento de Filosofia da Universidade do Estado do Rio de Janeiro (UERJ), Rio de Janeiro, RJ, Brasil. E-mail: fabianolemos@gmail.com. 
Lemos, F.

divisa física, mas também existencial - o que o fazia desistir de sua viagem a Londres e permanecer em Paris, mas também demonstrava que todo seu esforço de percorrer a literatura, a pintura, a ciência contemporâneas resultava, incontornavelmente, apenas na constatação de que nada havia sido aprendido, nada havia mudado de lugar, de fato. $\mathrm{O}$ mais distante que ele consegue ir da capital francesa é ainda próximo demais: em Fontenay, ao norte de Paris, ele sabe que deverá retornar em breve à sua cidade. Derrotado pela imobilidade que, invariavelmente, contorna o plano de suas ações, ele admite para si mesmo:

Dentro de dois dias estarei em Paris; então, feito isso, tudo está bem acabado; como um maremoto, as ondas da mediocridade humana sobem até o céu e vão engolir o refúgio cujos diques, contra minha vontade, eu abro. Ah! A coragem me falta e o coração me arrasta! - Senhor, tem piedade do cristão que duvida, do incrédulo que gostaria de crer, do escravo da vida que embarca sozinho na noite, sob um firmamento que não clareia mais as lanternas consoladoras da velha esperança! ${ }^{1}$.

Essas últimas palavras do personagem des Esseintes, do romance de 1884 A rebour (traduzido no Brasil como Às avessas), de Joris-Karl Huysmans, encerram em si uma espécie de programa que se desenha na literatura da belle époque. Evidentemente, não se trata de forçar uma convergência absoluta entre todos os textos produzidos entre 1871 e 1914, mas assinalar algo como uma tônica dominante no fin-de-siècle europeu através da qual os próprios escritores procuraram construir para si uma imagem. Entre o conflito franco-prussiano e a Grande Guerra, toda uma geração se debate diante das expectativas frustradas que o projeto de síntese cultural do Romantismo havia deixado como legado, não apenas politicamente, mas também simbolicamente. O personagem de Huysmans pensa,

1 HUYSMANS, K.-J. A rebours/Le drageoir aux épices, p. 335.

246 I Cad. Nietzsche, São Paulo, n. 33, p. 245-272, 2013. 
de forma metalinguística, sua posição diante da literatura que lhe é contemporânea, e só pode chegar à conclusão de que seu fracasso é o resultado inevitável que se abaterá sobre essa geração. Pessimista instável ou egoísta exasperado, não é por acaso que ele é lido, já pouco após a aparição do livro, como o decadente exemplar de seu tempo, de tal modo que Barbey d'Aurevilly poderá reconhecer nele "um dos mais decadentes que podemos contar entre os livros decadentes desse século decadente" ${ }^{\text {. }}$. Exemplo autoreconhecido da belle époque, o personagem de Huysmans denuncia o decadentismo ao mesmo tempo em que lhe investe - contra sua vontade, como lembra a passagem citada anteriormente - com a autoridade de um movimento literário ${ }^{3}$.

Qualquer tentativa de definir o decadentismo como a tônica desse período tem de lidar com seu aspecto limítrofe. Afinal de contas, a décadence se deixa entender, antes de mais nada, como um nexo de continuidade e um gesto de ruptura - concomitantemente - em relação ao Romantismo das décadas precedentes. Uma das imagens mais representativas do decadentismo é, na verdade, antecipada por Baudelaire, como lembra David Weir: em seu poema "Une Charogne", integrado em 1856 às Flores do mal, ele apresenta todos os signos caros à visão de mundo romântica - o esplendor da natureza, o arrebatamento diante da mulher amada, o idílio nostálgico de um passado em que tudo se integra, tudo se sintetiza. Mas, caminhando com a amante nesse cenário ideal, o poeta encontra, sobre as pedras, o cadáver em decomposição de um animal:

2 Citado por JUIN, H. "Préface" In.: HUYSMANS, J.-K. A rebours/Le drageoir aux épices, p. 16.

3 Cf. CALINESCU, M. Five Faces of Modernity: Modernism, Avant-Garde, Decadence, Kitsch and Postmodernism, pp. 211 e ss. Charles Bernheimer não utiliza o termo decadentismo, mas analisa seu campo semântico geral (cf. BERNHEIMER, C. Decadent Subjects. The Idea of Decadence in Art, Literature, Philosophy, and Culture of the Fin de Siècle in Europe, especialmente pp. 7-32 e 139-162 para o que nos concerne neste artigo). 
Lemos, F.

Lembra-vos do objeto que nós vimos, minha alma,

Aquela bela manhã de verão tão doce:

Na curva de um caminho, uma infame carniça,

Sobre um leito de pedregulhos,

As pernas viradas pro ar, como uma mulher lasciva,

Queimando e suando os venenos,

Abria de uma maneira descuidada e cínica

Seu ventre pleno de exalações.

E, no entanto, sereis semelhante a essa imundície,

A essa horrível infecção,

Estrela de meus olhos, sol da minha natureza,

Vós, meu anjo e minha paixão! ${ }^{4}$.

É justamente nesse encontro, que arranca o leitor, inesperadamente, da ordem perfeita da síntese romântica, que se instaura a decadência. Ela reside no confrontamento dispersivo entre a doçura de uma lembrança idealizada e um presente que se esvai, que se decompõe, e que contamina o passado. Tanto Huysmans quanto Baudelaire - e boa parte de seus contemporâneos - cultivaram essa dupla relação com sua época. Estendido entre o fim de um século e o começo de outro, o decadente representa, ao mesmo tempo, uma tendência e um desafio.

4 BAUDELAIRE, Ch. Oeuvres complètes, pp. 23-24. No original: "Rappelez-vous l'objet que nous vîmes, mon âme,/Ce beau matin d`été si doux:/Au détour d`un sentier une charogne infâme/Sur un lit semé de cailloux,/Les jambes en l'air, comme une femme lubrique,/ Brûlante et suant les poisons,/Ouvrait d'une façon nonchalante et cynique/Son ventre plein d'exhalaisons./(...) Et pourtant vous serez semblable à cette ordure,/À cette horrible infection,/Étoile de mes yeux, soleil de ma nature,/Vous, mon ange et ma passion!"'. Reproduzo aqui a análise de David Weir, Decadence and the making of Modernism, p. XI). 
Os leitores de Nietzsche podem reconhecer em seu texto, sem muito esforço, a repercussão desse diagnóstico geral. Obviamente, os termos décadence e décadent em Nietzsche se articulam a um léxico muito específico em que toda sua trajetória se encontra em jogo algo sobre o que retornarei mais adiante - mas que esses termos tão amplamente compartilhados tenham sido utilizados para se organizar tal léxico é algo que tem um sentido por si só. Como decadente e como antidecadente, o que no final das contas talvez signifique a mesma coisa, Nietzsche se coloca contra seu tempo apenas na medida em que é, profundamente, seu devedor ou seu herdeiro. A passagem do prólogo de $O$ caso Wagner que se refere a esse aspecto é bastante conhecida: "O que exige um filósofo em primeiro e em último lugar de si mesmo? Superar em si seu tempo, tornar-se 'atemporal [zeitlos]'. Com o que tem ele, portanto, de empreender seu mais duro combate? Com aquilo por meio do qual ele é filho de seu tempo. Pois bem! Sou, tanto quanto Wagner, um filho desse tempo, quer dizer, um décadent: mas eu concebi isso, mas eu me voltei contra isso. $\mathrm{O}$ filósofo em mim se voltou contra isso" (WA/CW, Prefácio, KSA 6.11).

É verdade que, diferentemente de des Esseintes, Nietzsche não afunda em sua cadeira, derrotado pelo seu tempo. Mesmo seu silêncio após o colapso de Turim pode ser lido como um confronto, uma tomada de posição ${ }^{5}$. A arbitrariedade de todas as coisas e o triunfo da ignorância, bem conhecidos por ele, ao menos desde a inauguração do teatro de Bayreuth $^{6}$, uma vez compreendidos, acabam por

5 Dois autores defendem mais enfaticamente a tese de que a loucura de Nietzsche pode ser entendida como uma estratégia filosófica. Pierre Klossowski afirma que a decisão de "transformar em loucura a própria lucidez" constitui uma extensão crítica contra a estabilização da razão sob a forma da certeza (KLOSSOWSKI, P. Nietzsche et le cercle vicieux, p. 86). Mais recentemente, Claudia Crawford defendeu, ainda que de modo não muito claro, a tese de que Nietzsche teria teatralizado sua loucura como modo de obter "acesso direto ao caráter catastrófico dos eventos da natureza" (CRAWFORD, C. To Nietzsche: Dionysus, I love you! Ariadne, p. 12; cf. também pp. 94-97).

6 Sobre a ruptura de Nietzsche com o modelo metafísico e existencial helenizante, schopenhaueriano e wagneriano, cf. LEMOS, F. "Nietzsche e a construção messiânica do wagnerianismo". In: TRANS/FORM/AÇÃO, vol. 33, n.2. O fragmento 9[42] do outono de 1887 (KSA 12.354-5) remete, sinteticamente, às condições dessa ruptura. 
Lemos, F.

libertá-lo da decadência de sua época. Mas o texto insiste: Nietzsche é ele, também, um décadent, pois esse combate - Strauss, no original - é, antes de tudo, consigo mesmo. Portanto, como des Esseintes, sua narrativa reúne "essa dupla ascendência [Herkunft], tanto do mais alto quanto do mais baixo degrau do caminho da vida, décadent e, ao mesmo tempo, começo" (EH/EH, Por que sou tão sábio, KSA 6.264), ainda que, em Huysmans, esse começo seja sempre adiado, frustrado, desviado. De partida, o que torna ambos décadents ideais é esse "desejo de se substrair de uma época odiosa de indignas grosserias" , ao mesmo tempo em que seu pertencimento ao fin-de-siècle se apresenta sempre como fronteira a ser cruzada.

Mas, se, por um lado, essa afindade pode ser identificada por leitores mais experientes, por outro, ela não passou desapercebida aos olhos de um público mais amplo. Já estão bem documentados e discutidos os questionáveis esforços operados por Elisabeth Förster-Nietzsche no sentido de consolidar toda uma mitologia em torno da vida e da obra de seu irmão insano - assim como o sucesso obtido por ela. ${ }^{8}$ Mas seria um equívoco atribiur exclusivamente a ela o alcance dessa mitologia nas décadas seguintes ao colapso de Turim. Mesmo sem lançarmos mão de uma tese contrafactual como a de Carol Diethe, segundo a qual "as ideias de Nietzsche se enraizariam mesmo sem os esforços de sua irmã", uma leitura mais atenta dos comentários sobre sua obra e sua vida, produzidos entre 1890 e 1914, nos ensina até que ponto a belle époque teve de fazer de tais ideias um espelho. A questão que resta ser esclarecida é justamente essa: a partir de que traços gerais a fraternidade decadentista entre des Esseintes e o autor que se automitologiza em Ecce Homo pode ser estabelecida. Ou seja, o que permitiu a um

7 HUYSMANS, K.-J. A rebours/ Le drageoir aux épices, p. 113.

8 Cf., por exemplo, JANZ, C. P. Friedrich Nietzsche. Biographie, Bd. 1, pp. 164-174,194-203;

DIETHE, C. Historical dictionary of Nietzscheanism, pp. 92-109; PETERS, Nietzsche et sa soeur Elisabeth, pp. 257-322.

9 DIETHE, 2007, p. XXII. 
crítico musical como o americano James Huneker, em 1909, publicar uma obra onde os nomes de Huysmans e Nietzsche - mas também os de Baudelaire, Stendhal, Anatole France, Barrès, Blake, Ibsen, Flaubert, Stirner e Ernest Hello - pudessem se encontrar em seu subtítulo? ${ }^{10}$ É verdade que nem todos os personagens elencados aí pertencem à belle époque, mas são, em todo caso, tratados como seus precursores. ${ }^{11}$ Mais ou menos que um contexto historico-social, a belle époque de Nietzsche se apresenta como um índice para a compreensão da relação entre os mecanismos de produção de seus textos e o destino hermenêutico que lhes foi dado.

\section{Ambiguidades do termo décadent}

Uma exigência metodológica se impõe, assim, no que se refere aos procedimentos de generaização da análise. Trata-se do problema da conceitualização da belle époque. Não pretendo, obviamente, empreender aqui um estudo sobre o decadentismo como movimento literário, mas apenas apresentar, em linhas muito gerais, alguns aspectos daquilo que, nesse movimento e para além dele, pode esclarecer alguns pontos do pensamento tardio de

10 O livro de Huneker chama-se, sintomaticamente, Egoists, a book of Supermen - Stendhal, Baudelaire, Flaubert, Anatole France, Huysmans, Barrès, Nietzsche, Blake, Ibsen, Stirner, and Ernest Hello e é uma compilação de estudos relativamente superficiais desses autores. Particularmente no que se refere ao capítulo sobre Nietzsche, sua leitura fundamenta-se quase exclusivamente nos depoimentos de seus amigos e emsua correspondência, sobretudo com Georg Brandes, a quem o livro é dedicado. Mesmo considerando que a intenção do texto é, fundamentalmente, biográfica, o uso limitado das fontes leva a uma série de distorções por parte de Huneker, como aquela em que Nietzsche aparece como alguém que levou a vida de um "santo" (HUNEKER, J. Egoists, a book of Supermen - Stendhal, Baudelaire, Flaubert, Anatole France, Huysmans, Barrès, Nietzsche, Blake, Ibsen, Stirner, and Ernest Hello, p. 261) ou quando se afirma uma improvável crença na "perfectibilidade humana" (Idem, p. 238).

11 No capítulo sobre Baudelaire, por exemplo, o ponto de partida é sua recepção pelas gerações seguintes, a "lenda de Baudelaire" (Idem, p. 67) e na seção sobre William Blake encontramos uma enfática comparação entre a moralidade de sua poesia e a da obra de Nietzsche (pp. 285-286). 
Lemos, F.

Nietzsche ${ }^{12}$. Como já sabemos, sob esse aspecto, o termo décadence e seus conexos assume uma importância central. Uma grande dificuldade, no entanto, em considerá-lo como índice de autorepresentação de uma cultura, reside na fluidez de sua semântica, que é diretamente proporcional à sua recorrência no vocabulário - sobretudo no vocabulário crítico - do fin-de-siècle europeu. Do ponto de vista estritamente conceitual, Richard Gilman pode estar certo ao afirmar que "não há nada a que ele realmente e legitimamente se aplique". ${ }^{13}$ Mas a décadence é menos um conceito que um ethos, e mesmo quando é abordada conceitualmente, isso sempre envolve um alto grau de ambiguidade - não como resíduo negativo, mas como parte do conceito. É o que acontece na definição en abyme de Barbey d'Aurevilly, quando enxerga em $A$ rebours o livro mais decadente de todos os decadentes em um século decadente. Muito pouco palpável, essa afirmação é, antes, ela mesma, derivada do decadentismo do próprio Aurevilly, enquanto sua enfática artificialidade conduz seu leitor a esse horizonte paroxístico e de esgotamento do real, que não pode ser compreendido senão como um gesto. Não devemos, portanto, simplesmente abrir mão do termo e, como sugere Gilman, exclui-lo do léxico crítico, mas considerar, positivamente, seus impasses intrínsecos.

Essa observação metodológica se aplica, ainda, exemplarmente, no caso específico de Nietzsche. Seu uso da palavra décadence, multiplicado, sobretudo, ao longo de 1888, apresenta uma variação tão ampla que Charles Bernheimer pôde afirmar que, a seu respeito, nem mesmo Nietzsche tinha uma ideia totalmente

12 Para um estudo detalhado da questão, limito-me a remeter ao livro de David Weir, Decadence and the making of Modernism (1995).

13 Citado em BERNHEIMER, C. Decadent Subjects. The Idea of Decadence in Art, Literature, Philosophy, and Culture of the Fin de Siècle in Europe, p. 4.

252 I Cad. Nietzsche, São Paulo, n. 33, p. 245-272, 2013. 
clara. ${ }^{14}$ Se tomarmos como exemplos alguns fragmentos póstumos desse período isso se deixa perceber bastante nitidamente. No começo de 1888, Nietzsche anota em seu caderno pessoal:

“décad[ence]

O que se herda não é a doença, mas o doentio [Kranhaftigkeit]: a impotência na oposição contra o perigo de imigrações perniciosas etc.; a força de oposição rompida - expressa moralmente: a resignação e a humildade diante dos inimigos.

Eu me pergunto se não se pode comparar todos esses valores superiores da filosofia moral e da religião até agora com os valores dos enfraquecidos, dos doentes mentais e neurastênicos: eles constituem, em uma forma mais sutil, o mesmo mal... (...)

O enfraquecimento como tarefa: enfraquecimento dos apetites, dos sentimentos de prazer e desprazer, da vontade de poder, do sentimento de orgulho, de querer ter e querer-ter-mais; o enfraquecimento como humildade; o enfraquecimento como fé; o enfraquecimento como rejeição e vergonha em tudo o que é natural, como negação da vida, como doença e fraqueza habitual" (Nachlass/ FP 1888, 14[65] KSA 13.250-251).

Essa associação entre o décadent e o doente - sobretudo o doente dos nervos - é bem conhecida dos leitores de $O$ caso Wagner, onde ela funciona mesmo como tese central. ${ }^{15}$ Mas ela também é recorrente nos escritos do simbolismo da belle époque, que apresentou, como nenhum outro período, um enorme asilo de enfermos. Des Esseintes sofre, segundo seus médicos, de um tédio neurótico; muitos personagens de Proust refletem suas leituras de tratados

14 Cf. Idem, p. 8.

15 Cf., por exemplo, WA/CW 5, KSA 6.21: "O artista da décadence - eis a palavra. E com ela começa minha sobriedade. Estou longe de observar inofensivamente enquanto esse décadent nos estraga a saúde - e, além disso, a música! Wagner é realmente um homem? Ele não é, antes, uma doença? Ele faz tudo em que toca ficar doente, - ele faz a música ficar doente -". 
Lemos, F.

sobre neurastenia e outras psicopatologias; ${ }^{16}$ algumas mulheres das novelas e romances de Zola, Maupassant, Flaubert e dos irmãos Goncourt são retratos inspirados na amplamente conhecida iconografia fotográfica do hospício de Saltpêtrière ${ }^{17}$ - e a lista aqui ainda poderia se estender, indefinidamente, da narrativa confessional da experiência da loucura de Rimbaud à neurose entediada do Igitur de Mallarmé. É verdade que as vertigens da loucura, da doença e da morte já estavam presentes no Romantismo das décadas precedentes, tanto na Alemanha - como é o caso com $O$ homem da areia, de Hoffmann ou o Empédocles, de Hölderlin - quanto na França, com os delírios da prosa de Nerval ou das narrativas fantásticas de Téophile Gautier. Mas entre os românticos, o discurso do doente, físico ou mental, se confunde com o místico, e representa, antes de tudo, um lugar de síntese. A dissolução de Empédocles no vulcão correspondia, em Hölderlin, a uma tese sobre o Absoluto, sobre o retorno ao $U r$-Eine - algo que obcecava ainda o jovem Nietzsche em $O$ nascimento da tragédia (cf. GT/NT, 1, KSA 1.30). Com a emergência das estratégias narrativas da belle époque - e, no caso de Nietzsche, com a ruptura mais enfática com os modelos românticos de sua juventude - o doente passa a encarnar, antes, o degenerado, o enfraquecido, e o caráter místico cede lugar à experiência cotidiana dos limites do corpo. Se Rimbaud pode falar de "encantamentos" que condicionam seus atos, é porque especifica-os logo em seguida: trata-se de "encantamentos sobre meu cérebero", e por mais "sagrada" que pareça a "desordem do meu espírito" é ao corpo e suas mazelas que ela conduz ${ }^{18}$. Do mesmo modo, Igitur faz conicidir o

16 Cf. FINN, M. R. Proust, the Body and Literary Form, pp. 10 e ss.

17 Cf. SICARD, M. "La femme hystérique: émergence d'une representation” In: Communication et languages, n. 127, p. 39. Evidentemente, a adesão a um modelo clínico para explicação das paixões humanas não foi homgênea. Maupassant, por exemplo, em seu artigo de 1882 Une femme, acusa Charcot, a quem chama de "grande padre da histeria" de somatizar patologicamente qualquer sentimento (cf. MAUPASSANT, G. de "Une femme". In: Chroniques, t. 2, p. 111).

18 Cf. RIMBAUD, A. Poésies. Une saison em enfer. Illuminations, pp. 145 e 141, respectivamente.

254 I Cad. Nietzsche, São Paulo, n. 33, p. 245-272, 2013. 
Absoluto com a neurose e o tédio ${ }^{19}$. Sob esse aspecto, o décadent é o antípoda do romântico. E, mesmo que Nietzsche tenha, em muitas passagens, aproximado os dois, a rejeição do Romantismo como enfraquecimento não é suficiente para que esqueçamos, no jovem Nietzsche, um movimento oposto. $\mathrm{O}$ que os textos tardios promovem é um distanciamento de sua própria escrita com a narrativa romântica ${ }^{20}$, e é bastante comum em Nietzsche esse procedimento a partir do qual todo resíduo de um passado que ele deve rejeitar segundo suas premissas morais cada vez mais singulares (Kant, Schopenhauer, Wagner) é expurgado em campos semânticos tão recorrentes quanto imprecisos - niilismo, decadência, modernidade etc. A identificação do ethos decadente como doença resulta, assim, de um longo exercício diagnóstico, onde sua trajetória passa a ser compreendida como um conjunto de sintomas, e essa compreensão mesma constitui a única forma de cura possível.

Foi Wolfgang Müller-Lauter quem procurou demonstrar como esse diagnóstico da décadence, instanciada esteticamente, segundo

19 Cf. MALLARMÉ, S. Oeuvres complètes, p. 439.

20 Cf., por exemplo, outro fragmento do começo de 1888 (KSA 13, 463): "De fato, os românticos representam uma forma de décadence doentia (...)". Não teríamos como tratar aqui suficientemente dos limites do pertencimento de Nietzsche ao Romantismo. Há uma bibliografia realmente vasta sobre o tema, que discuti em um artigo recente (LEMOS, F. "Nietzsche e a construção messiânica do wagnerianismo". In: TRANS/FORM/AÇÃO, vol. 33, n.2). Seria útil, no entanto, ao menos assinalar minha hipótese geral nesse sentido: há, por um lado, em Nietzsche, desde $O$ nascimento da tragédia, uma rejeição sistemática de duas características elementares do Romantismo - a idealização da natureza e a naturalização do ideal. Tais características são remetidas, primeiramente, a Rousseau e, com o passar dos anos, por extensão, a Wagner e a todos os décadents. É contra a Weltanschauung romântica que Nietzsche se posiciona, portanto. Mas há, no entanto, ao menos nos primeiros textos, uma circunscrição bastante clara de seu estilo e de seus procedimentos narrativos em geral - seus modelos de argumentação, sua construção simbólica, seu uso da linguagem metafórica etc. - no contexto de autores como Goethe, Schiller, Hölderlin, Novalis, e mesmo Schelling. Embora nem todos possam ser considerados precisamente românticos - uma inscrição sempre difícil, mesmo nos casos mais óbvios ou autodeclarados - suas escritas giram em torno de certos procedimentos que, ao longo do século XIX receberam uma função fundamental na constituição do estilo romântico. Assim, considero que as obras de Nietzsche anteriores à sua ruptura com Wagner permitem enxergar uma filiação à poética romântica, que será rejeitada nos últimos livros, o que complexifica sua atitude anti-romântica.

Cad. Nietzsche, São Paulo, n. 33, p. 245-272, 2013. I $\mathbf{2 5 5}$ 
Lemos, F.

Nietzsche, em Richard Wagner, se caracteriza por uma análise em termos fisiológicos. ${ }^{21}$ É ele, também, quem nos indica a principal fonte das reflexões do final da década de 1880: Paul Bourget e seus Essais de Psychologie Contemporaine, de $1883^{22}$, que Nietzsche havia lido uma primeira vez no inverno de 1883/1884. ${ }^{23} \mathrm{O}$ livro, uma coletânea de ensaios sobre Baudelaire, Renan, Flaubert, Taine e Stendhal, foi lido com vivo interesse por Nietzsche, referido frequentemente em sua correspondência (cf. KSB VII, 18, 59, 120, 171 etc.) citado diretamente em Ecce Homo (EH/EH, Porque sou tão inteligente, 3, KSA 6.285) e analisado em seus cadernos pessoais (Nachlass/ FP, KSA 13.134; 642; 14.405; 698 etc.). Embora relativamente pouca atenção tenha sido dada a essa fonte, ela é, certamente, fundamental. Bourget representou um modelo emergente de escrita que se dedicou a explorar o discurso clínico e psicológico como matrizes de explicação do próprio poético, e, com isso, causou profunda impressão entre os escritores às vésperas do século XX - e o modo como Nietzsche também se apropriou desse novo vocabulário em seus últimos textos nos informa sobre o grau de seu pertencimento a uma época que, por outro lado, ele condenava. ${ }^{24}$ Talvez a passagem mais significativa, nesse sentido, seja a seção III do ensiaio de Bourget sobre Baudelaire, intitulada Teoria da decadência. Aí, é apresentada uma definição do termo que se desloca nitidamente do horizonte romântico para o fisiologismo insistente da belle époque:

21 Cf. MÜLLER-LAUTER, W. "Décadence artística enquanto décadence fisiológica. A propósito da crítica tardia de Friedrich Nietzsche a Richard Wagner”. Trad. Scarlett Marton. In: Cadernos Nietzsche, n. 6, 1999.

22 Idem, p. 12.

23 Cf. BROBJER, Th. "Nietzsche's Reading and Private Library, 1885-1889". In: Journal of the History of Ideas, Vol. 58, No. 4, p. 679.

24 David Wachter chamou a atenção para as correspondências entre um certo conjunto de termos utilizados por Nietzsche em suas críticas ("doença [Krankheit]", "deterioração [Verfall]”, "corrupção [Verderbnis]", "infecção [Infektion]") e a "abordagem fisiológica que emerge no século XIX" (cf. WACHTER, D. "Die Ambivalenz der décadence. Nietzsche, Bourget und Wagner". In: Focus on German Studies, n. 9, p. 143).

256 I Cad. Nietzsche, São Paulo, n. 33, p. 245-272, 2013. 
Pela palavra decadência, designa-se, antes, o estado de uma sociedade que produz um número muito grande de indivíduos impróprios ao trabalho da vida comum. Uma sociedade deve ser assimilada a um organismo. Como um organismo, com efeito, ela se resolve em uma federação de organismos menores, que se resolvem eles mesmos em federações de células. $O$ indivíduo é a célula social. Para que o organismo total funcione com energia, é preciso que os organismos que o constituem funcionem com energia, mas com uma energia subordinada; e para que esses organismos menores funcionem eles mesmos com energia, é necessário que as células que os constituem funcionem com energia, mas com energia subordinada. Se a energia das células se torna independente, os organismos que compõem o organismo total cessam, igualmente, de subordinar sua energia à energia total e a anarquia que se estabelece constitui a decadência do conjunto ${ }^{25}$.

Por mais que essa passagem pareça retomar uma posição expressa no Romantismo - por exemplo, na teoria política de Wilhelm von Humboldt - já não se deixa advinhar aqui o traço de nenhum Geist, de nenhuma totalidade além daquela observável fisicamente. A geração de Schopenhauer se enfurecia com o avanço de uma cultura da especialização, da segregação individualizante - e os textos de Nietzsche da época de $O$ nascimento da tragédia ainda darão um último fôlego a esse tipo de pessimismo. É certo que o fin-de-siècle de Huysmans se nutriu dessa fonte - devemos lembrar que des Esseintes é um leitor ávido de Schopenhauer? Mas o pessimismo das décadas seguintes se voltava de um modo diferente contra a desagregação da cultura. Se é verdade que as noções de organismo e organicaidade eram centrais entre os românticos, aqui elas ganham um nova e dupla determinação: não mais uma ideia metafísica, mas uma lei política e biológica ${ }^{26}$. A crítica que Nietzsche havia empreen-

25 BOURGET, P. Essais de psychologie contemporaine, pp. 24-25.

26 Cf. MOORE, G. Nietzsche, biology and metaphor, p. 116: "Mas o que distinguiu o pessimismo do fin-de-siècle daquele das gerações precedentes era que a ideia de decadência havia se tornado agora tanto puramente conceitual quanto médica". 
Lemos, F.

dido, desde muito cedo, mas de modo muito geral, contra a ideia de anarquia (cf. BA/EE 2, KSA 1.683), se especifica nos últimos textos, reverberando a tese de Bourget, como uma crítica contra um sintoma cultural e psicológico, que, pode, enfim, reunir tudo o que é anárquico e wagneriano sob uma mesma tipologia - como procuram demonstrar certas passagens de $O$ caso Wagner ${ }^{27}$.

Mas é precisamente em torno do problema da fragmentação, inscrito na própria definição de decadência, fornecida por Bourget e retomada por Nietzsche, que encontramos uma incontornável e positiva ambiguidade, própria da literatura da belle époque, mas também das análises contemporâneas a Ecce Homo. Frequentemente se sublinhou o caráter crítico do diagnóstico de Nietzsche em tornon da decadência, o que, de fato, o distancia de autores como Huysmans ou mesmo Baudelaire. Mas é preciso lembrar que é parte do processo de libertação da decadência tornar-se decadente - algo sobre o que Nietzsche não deixou de insistir. É o caso de um fragmento póstumo redigido também no começo de 1888, onde se lê:

conceito "décadence"

O dejeto, a deterioração, o expurgo [Abfall, Verfall, Ausschluss] não é nada que seria condenável: é apenas a consequência da vida, do crescimento na vida. $\mathrm{O}$ fenômeno da décadence é tão necessário quanto qualquer emergência e prosseguimento da vida: não é possível ter em mãos o poder de eliminá-la. A razão quer, inversamente, que ela [a décadence] se torne o seu direito... (Nachlass/ FP 1888, 14[75], KSA 13.255-256).

Aqui, mais uma vez, a aproximação com o ensaio de Bourget sobre Baudelaire é útil. Sua sistematização de uma fisiologia da

27 Cf. WA/CW 7, KSA 6.27-28. Müller-Lauter apontou para o modo como a crítica tardia a Wagner reproduz, quase literalmente, certas passagens do livro de Bourget. Cf. MÜLLERLAUTER, W. "Décadence artística enquanto décadence fisiológica. A propósito da crítica tardia de Friedrich Nietzsche a Richard Wagner". Trad. Scarlett Marton. In: Cadernos Nietzsche, n. 6,1999, p. 13. 
literatura expressa uma tendência muito geral da virada do século XIX para o XX em que o doentio, o mórbido, o anormal devem ser compreendidos como modulações do saudável, do regular, do normal - e, assim, reinscitos no quadro esquadrinhado, tanto da biologia quanto da cultura. Ao final, do ponto de vista do olhar literário do período, a doença se manifesta como expressão do corpo. Bourget é bastante explícito quanto a isso:

Não existem propriamente doenças do corpo, dizem os médicos; não existem senão estados fisiológicos, funestos ou benéficos, sempre normais, se se considera o corpo humano como o aparelho onde se combina uma certa quantidade de matéria em evolução. Paralelamente, não há doença nem saúde da alma, não existem senão estados psicológicos, do ponto de vista do observador sem metafísica, pois ele não percebe em nossas dores e em nossas faculdades, em nossas virtudes e em nossos vícios, em nossas volições e em nossas renúncias, senão combinações, mutantes, mas fatais, e, para tanto, normais, submetidas às leis conhecidas da associação de ideias ${ }^{28}$.

Do ponto de vista de um observador sem metafísica, de um psicólogo da moralidade como pretende Nietzsche, a decadência se apresenta como uma forma de expressão da vida mesma, e o estado fragmentário, como uma condição expressiva. Dito de outro modo, a degeneração constitui uma performance da vida.

\section{Perfomatividade como estratégia narrativa}

Wagner havia sido uma doença para Nietzsche - ao menos é o que se afirma retrospectivamente no prefácio de $O$ caso Wagner - mas também uma condição para a cura [Genesung] (WA/CW,

28 BOURGET, P. Essais de psychologie contemporaine, p. 12.

Cad. Nietzsche, São Paulo, n. 33, p. 245-272, 2013. I 259 
Lemos, F.

Prefácio, KSA 6.12). Nem sempre o doentio havia ocupado esse lugar na filosofia de Nietzsche - basta, para isso, lembrarmos, das duras críticas àquilo que se denominou, na década de 1870 , a "doença histórica", característica do hegelianismo (cf., por exemplo,HL/ Co. Ex. II, KSA 1.329, 331, 332 etc.). Ainda assim, tal revalorização da doença é, no entanto, bem anterior; ela precede, inclusive, a leitura que Nietzsche havia feito de Bourget - embora se intensifique com ela. Isso porque, já no prólogo de A gaia ciência, em 1882, a tarefa filosófica a que se propõe o livro é apresentada nesses termos: ela vem substituir uma "má compreensão [Missverständniss] do corpo", por uma outra, adequada, em que a doença é considerada como algo benéfico. "Advinha-se que eu não queira dar adeus com ingratidão àquele tempo de grave enfermidade, cujo benefício, ainda hoje, não se esgotou para mim: tanto quanto estou bem ciente de que, em minha saúde instável, estou à frente de todos os bem-constituídos do espírito" ${ }^{29}$ Uma posição semelhante é mantida um pouco mais tarde, quando Nietzsche, em seu Ensaio de autocrítica de $O$ nascimento da tragédia, nos informa que a obra havia nascido durante um estado de convalescença que, não por acaso, levou a um estado mais profundo de reflexão (cf. GT/NT, Tentativa de autocrítica, KSA 1.11).

Mas há também um outro aspecto na degeneração doentia, que nós poderíamos denominar metodológico: a doença é o lugar de um novo perspectivismo. É isso que também anuncia a passagem do prefácio de A gaia ciência: "Um filósofo que percorreu, e sempre torna a percorrer, o caminho através de muitas saúdes, também atravessou, igualmente, muitas filosofias: ele não pode nada além de transpor seu estado, toda vez, para a forma e a distância mais espirituais" (FW/GC, Prefácio à segunda edição, 3, KSA 3.349). Para utilizar uma expressão de David Wachter, esse "conceito

29 KSA 3.349. Cf. também o fragmento 15 [31], de 1888, em KSA 13.426-427: “A própria décadence não é algo com que se deveria lutar: ela é absolutamente necessária a cada tempo e a cada povo em particular".

260 I Cad. Nietzsche, São Paulo, n. 33, p. 245-272, 2013. 
perspectivista" ${ }^{90}$ da doença/saúde instaura não apenas uma reconfiguração psicológica, potencialmente egoísta, como críticos de Nietzsche como Lukács iriam denunciar, mas uma nova maneira de se pensar a filosofia - o que talvez seja ainda mais grave aos olhos desses mesmos críticos. Não se trata, portanto, de um ego como condição da filosofia, mas como efeito, multiplicado indefinidamente, da renovação de sua tarefa. A decadência desagrega a unidade do organismo, mas, ao fazer isso, permite ao orgânico se reorganizar sob novas formas, empurrando cada vez mais para longe as regras e os limites da constituição do pensamento. ${ }^{31} \mathrm{Se}$ abandonarmos a perspectiva, herdada de leitores como Erich Podach, segundo a qual os últimos textos de Nietzsche devem ser considerados como sintomas de sua insanidade, podemos pensar suas personificações nessas obras e em sua correspondência como um esforço radical de perspectivação através da doença e do confronto com ela. "Dioniso contra o crucificado" (EH/EH, Porque eu sou um destino, 9, KSA 6.374), "Dioniso (KSB 8.571, 574 etc.)", "O crucificado" (Idem, 572, 573 etc.), "Nietzsche Caesar" (Idem, 568), "Astu" (Idem, 578), ou mesmo esse "Friedrich Nietzsche" que consta, ainda, dos inúmeros projetos de capa de seus livros de 1888 (Nachlass/FP, KSA 13.586, 589 etc.), passam a surgir como resultado da dimensão potencializadora da decadência, de sua possibilidade de performatizar esses nomes.

É preciso deixar claro que, antes de tudo, essa performatividade não pode ser confundida com uma teatralização qualquer. O filósofo decadente sabe que é decadente, ele não quer criar quaisquer ilusões, mas desfazê-las em um jogo incessante de personificações; por outro lado, aquele que finge para os outros e para si mesmo continua sendo sempre e apenas um ator, um Schauspieler - um wagneriano.

30 Cf. WACHTER, D. "Die Ambivalenz der décadence. Nietzsche, Bourget und Wagner". In: Focus on German Studies, n. 9, p. 146.

31 É essa, também, até onde vejo, a tese de David Wachter sobre Nietzsche (Idem, p. 150: “A reorganização do organismo leva a uma nova totalidade (...))". 
Lemos, F.

Se compararmos as insistentes acusações de $O$ caso Wagner nesse sentido com o parágrafo 324 de Aurora, intitulado Filosofia dos atores, conseguimos compreender qual o problema com Wagner: ele quer ser tomado como um clarividente, quando na verdade não passa de um "macaco ideal” (M/A 324, KSA 3.231), cuja imitação não apresenta nada de essencial, ao contrário do que suas óperas pretendem. Somente esse macaco pode ser acusado de egoísmo - tudo nele é o contrário de uma revelação, da suposta clarividência que ele sustenta possuir; tudo nele é, antes, dissimulação e disfarce ${ }^{32}$. Ao contrário, a performatividade da decadência na belle époque deve ser compreendida como um método de modulação infinita do psicológico, de tal modo que não é possível mais reclamar os direitos soberanos de uma subjetividade plenamente desenvolvida, estática, sintetizadora. O projeto de Proust em Em busca do tempo perdido instancia precisamente essa performatividade enquanto representa, ao mesmo tempo, uma dimensão estilística e existencial. Seu narrador, personagem sem nome e sem idade, que nunca se revela ao seu leitor através de uma identidade qualquer senão aquela, instável, do seu desejo e de sua memória, sabe que a procura pelo passado está condenada ao fracasso; diante dela "todos os esforços de nossa inteligência são inúteis". ${ }^{33}$ Derrotado por um tempo perdido - e que não para de se perder - esse narrador se inscreve em um espaço de incerteza onde "o espírito se sente ultrapassado por ele mesmo"34. A voz proustiana é modulada, portanto, nos limites imprecisos desse espaço. Deleuze assinalou esse ponto ao tratar da questão do estilo em Proust: "o essencial é que as partes de À procura permanecem despedaçadas, fragmentadas, sem que nada lhes falte: partes eternamente parcias levadas pelo tempo, caixas entreabaertas e vasos fechados,

32 A caracterização de Wagner como ator havia sdo empreendida muito cedo, como demonstra um fragmento de 1874 (Nachlass/FP 1874, 32 [10], KSA 7.756), ainda que de modo não tão enfaticamente pejorativo.

33 PROUST, M. À la rechereche du temps perdu, p. 44.

34 Idem, p. 45.

262 I Cad. Nietzsche, São Paulo, n. 33, p. 245-272, 2013. 
sem formar um todo nem supor um, sem faltar nada nesse despedaçamento, e denunciando, antes de tudo, toda unidade orgânica que se quisesse aí introduzir"35.

Compreendido performativamente, esse mecanismo de anonimato e dispersão não é o oposto do personalismo de autores como Baudelaire, Huysmans, Verlaine etc. Se seus personagens têm um nome, um rosto, se se lê em seus romances e novelas uma defesa insistente do individualismo, isso se dá apenas porque esse indivíduo se revela, ele mesmo, fragmentado, em conflito. A identidade de des Esseintes, por exemplo, se dá no nível de seu modo de pensar, de seu estilo. Em última análise, o processo de anonimização e fragmentação é justamente o que permite a emergência prismática de um Eu, que, separado de um todo, só pode afirmar sua própria existência. Do ponto de vista de sua própria constituição, esse procedimento deriva da decadência, da doença. ${ }^{36}$ Apontou-se frequentemente a dimensão unificadora - embora oblíqua - de Ecce Homo ${ }^{37}$ mas pouco tem sido dito quanto ao seu caráter performático. Não se poderia ler nas afirmações mais contundentes do livro, nas autorepresentações mais luminosas, também seu contrário - ou seja, um esforço de modulação do autor, da obra e mesmo do leitor? Embora não pretenda me deter nesse ponto, é importante notar que a questão da assinatura do livro ao menos sugere a necessidade de se investigar esse problema.

35 DELEUZE, G. Proust et les signes, p. 193.

36 Vemos bem que se trata de algo muito diferente do culto à persanalidade que o Romantismo de Hölderlin e do jovem Nietzsche ainda articulava.

37 Mesmo nas tentativas, certamente bem-sucedidas, de afastar o livro de uma insistente desqualificação, seja como "apenas literatura", seja como o texto contaminado de um insensato, a necessidade de uma síntese explicativa geral parece ser inescapável. Cf., por exemplo, GASCHÉ, 1981. Uma notável exceção a essa perspectiva, se encontra em SILVERMAN, H. J. "The Autobiographical Textuality of Nietzsche's Ecce Homo". In: boundary 2, Vol. 9, No. 3, especialmente pp. 144-147. 
Lemos, F.

Dois elementos em jogo nesse egoísmo performatizado dos decadentistas nos ajudam a entender seu antagonismo em relação a suas formas ideologizadas: a conversão e o culto à artificialidade.

No que diz respeito ao primeiro, ele faz parte da lógica segundo a qual o decadente precisa, como parte fundamental de seu ethos, se colocar contra si mesmo. São duas, pelo menos, as vozes que testemunham, concomitantemente, no discurso literário da belle époque - frequentemente assumindo a forma de uma voz do passado e outra do presente. A nostalgia letárgica de Proust é o melhor exemplo desse procedimento. Mas, mais do que isso, esse confronto polifônico se dá, muitas vezes, sob o signo da mudança radical: como se a voz do presente tivesse de, em seu desenvolvimento mesmo, rasurar a do passado e lhe conferir um novo sentido. A conversão ao catolicismo de Huysmans é justificada, assim, no prefácio redigido vinte anos após a primeira edição de $A$ rebours: "após um tal livro, nada mais resta ao autor senão escolher entre o cano de uma pistola ou os pés da cruz. A escolha está feita" ${ }^{38}$ São exatamentes esses os signos da conversão à saúde que se revelam em Ecce Homo - uma escolha que não é o contrário da decadência, mas seu resultado. Em outras palavras, a lógica da decadência é a conversão, e, sua posição, tão enfática quanto a expectativa em suspenso de um nova configuração de forças: "Pois, levando em conta que sou um décadent, sou também o seu contrário. (...) Tomei a mim mesmo em mãos, fiz de mim mesmo saudável novamente: a condição para isso - todo fisiólogo admitirá isso - é que se seja, no fundo, sadio" (EH/EH, Porque sou tão sábio, 2, KSA 6.266).

Em segundo lugar, o artificial passa a ocupar, na nova sensibilidade do fim do oitocentos, uma função explicativa central na literatura, relativizando a ideia romântica de natureza. Não se trata aqui simplesmente, mais uma vez, de oposição. Precocemente, Baudelaire talvez tenha sido o poeta que tenha levado ao mais

38 HUYSMANS, J.-K. À rebours, p. 46.

264 I Cad. Nietzsche, São Paulo, n. 33, p. 245-272, 2013. 
extremo a identificação entre os dois polos. É nesse sentido que sua defesa da "eterna superioridade do dândi" 39 gira em torno de sua capacidade de diagnosticar o artifício e de repercutí-lo, ampliando-o. Desse modo, compreendemos melhor a ironia que funciona ao fundo de sua famosa observação em Meu coração desnudado [Mon coeur mis à $n u]$, composto, provavelmente no início da década de 1860, mas publicado apenas postumamente: “Aquilo que sempre achei mais belo em um teatro, desde minha infância, e até agora, é o lustre (...)"40. No teatro, o lustre é o signo de um deslocamento no campo da verdade dramática, que deve deixar de procurar seu valor naquilo que ela deveria representar, e deve deixar, mais fundamentalmente, de apagar os vestígios da artificialidade do deus ex machina. O verdadeiro teatro, segundo Baudelaire, é aquele que, antes, sublinha o caráter performativo do ator, e, por isso, tem de se prescrever a ele que os atores usem máscaras "mais expressivas que o rosto humano", que andem sobre grandes saltos, que falem através de porta-vozes, que, enfim, os papéis femininos sejam representados por homens. ${ }^{41}$ Em cada um desses casos, o que está em jogo é o caráter residual de um artifício que, ao se tornar presente, distancia o público da obra. Ora, o que choca os leitores de Baudelaire é o fato de que a perfeita simetria geométrica do lustre, no entanto, não antagoniza, essencialmente, com as belezas naturais, embora o faça, muitas vezes, estilisticamente. $O$ elo de ligação aqui é a figura do excremento, da sujeira, do resto. A carcaça em decomposição encontrada no meio do caminho durante o passeio com sua amada também guarda em si essa dupla determinação: ela

39 BAUDELAIRE, Ch. Oeuvres complètes, p. 408.

40 Idem, p. 409. Analisando essa passagem, Marcos Siscar conclui: "Em Baudelaire, a impostura - tanto no que ela envolve de engano quanto de afronta - é um modo da postura. A retórica da verdade, reforçada pelos traços aforismáticos, incide sobre afirmações de caráter altamente artificioso, e ganha, assim, um caráter da provocação, uma maneira de potencializar aquilo que Baudelaire chama de "mal-entendido"” (SICARD, “Responda, cadáver': o discurso da crise na poseia moderna". In: Alea, vol. 9, n. 2 2007, p. 184).

41 Idem. 
Lemos, F.

é algo e deixa de ser algo; assim como a máscara, que, no jogo da representação, se apresenta como um resto, intermediário entre o real e o ilusório.

Ao longo da década de 1880, Nietzsche se mostrou especialmente interessado na questão do excremento como ponto de partida para a análise dos processos de purificação ideológica. No final de 1887 ele anota em seu caderno uma passagem de Baudelaire extraída exatamente de Meu coração desnudado: “O francês é um animal de fossas, tão bem domesticado, que não ousa atravessar nenhum muro. (...) É um animal de raça latina: a imundície não o desagrada, em seu domicílio e em literatura, ele é escatófago. Ele rola sobre seus excrementos". ${ }^{42}$ Essa anotação reverbera incontáveis ocorrências da palavra Koth, excremento, em sua obra nesse período. Em geral, o termo surge como antagonista para uma sensibilidade refinada que é, em seguida, desconstruída como falsa. O nojo da imundície se manifesta, assim, como um enfraquecimento imposto por uma moralidade castradora, que pretende separar o puro do impuro sob a mesma lógica da distinção entre o artificial e o natural. Na passagem de Zaratustra intitulada "De velhas e novas tábuas" é desse modo que a questão é colocada: "Há sabedoria no fato de que muitas coisas no mundo cheiram mal: o próprio asco gera asas e forças que pressentem fontes! Mesmo no melhor ainda há algo que gera asco; e ainda o melhor é algo que tem de ser superado! Ó, meus irmãos, há muita sabedoria no fato de haver muita sujeira no mundo! -" (ZA/ZA, De velhas e novas tábuas, 14, KSA 4.257). O natural é conduzido, assim, ao domínio do expurgo, daquilo que, sob a ótica do idealista pode surgir como descartável.

42 Nachlass/FP 1887, 11 [161], KSA 13.75. A passagem encontra-se em BAUDELAIRE, 1980 , p. 419.

266 | Cad. Nietzsche, São Paulo, n. 33, p. 245-272, 2013. 
IV. Os perigos do egoísmo

Seja como for, o egoísmo performativizado é algo bastante diferente do egoísmo como ideologia, mas a confusão entre ambos foi o que permitiu a uma série de críticas, contemporâneas da belle époque, encontrar em seus autores os sinais de uma ameaça social. É exatamente como "idealen Decadenten" que Max Nordau, em seu Entartung [Degeneração], de 1892, procura descrever Des Esseintes - e justamente na medida em que essa apresentação lhe serve de álibi para condenar seu autor e toda sua geração. ${ }^{43} E$ compreensível, portanto, que Huysmans surja no texto de Nordau, portanto, logo em seguida, como "o tipo clássico [der klassische Typus] de histérico sem originalidade". ${ }^{44}$ É também o caso de Josef Viktor Widmann, que redige, ainda em 1886, uma resenha intitulada Nietzsches gefährliches Buch [O livro perigoso de Nietzsche], texto amplamente lido, que tratava Além do bem o do mal como uma obra que atacava os valores democráticos e que estava repleta de "falsas declarações" ${ }^{45}$ posição que será retomada ainda nas leituras de Lukács, já após a Segunda Guerra. Além disso, um número considerável de peças que satirizavam as teses filosóficas de Nietzsche passaram a ser encenadas por toda a Alemanha, e já associava tais teses a um modelo político retrógrado e ameaçador. ${ }^{46} \mathrm{O}$ historiador da filosofia kantiano Friedrich Paulsen foi ainda mais enfático:

43 Cf. NORDAU, M. Entartung, 2. Bd, p. 106.

44 Idem.

45 Citado em HILLEBRAND, B. (hrsg.) Nietzsche und die deutsche Literatur, Bd. 1, p. 60. O texto de Widmann é logo resenhado, como mostra KRUMMEL, 1998, p. 131. A crítica de Widmann foi recebida com certo entusiasmo por Nietzsche: apesar de negativa, ela parecia lhe servir como propaganda, de tal modo que "ninguém pode sentir uma inclinação mais forte a pensar em comprar [o livro] que aquela produzida por este artigo" (KSB VII, 249). Além disso, Nietzsche se apropriará, mais tarde, em Ecce Homo, do modo como Widmann se refere a ele em seu artigo, onde qualifica seu pensamento como "dinamite" (cf. citação em HILLEBRAND, op. cit., p. 58; ver EH/EH, Porque eu sou um destino, 1, KSA 6.365 e BISHOP, P. (ed.) A companion to Freidrich Nietzsche: life and works, p. 251).

46 Cf. NICHOLLS, R. A. "Beginnings of the Nietzsche Vogue in Germany". In: Modern Philology, Vol. 56, No. 1, pp. 24-37. 
enxergava na "febre Nietzsche" que assolava a juventude, já em 1904, um "teatro estranho" e a "neurastenia da época". ${ }^{47}$ Por fim, quando o assassino do arquiduque Franz Ferdinand, Gavrilo Princip, se revelou um leitor entusiasmado do nietzschanismo da belle époque, o ódio dos britânicos e americanos encontrou não exatamente uma justificação, mas um álibi para uma reação há muito tempo fomentada. ${ }^{48}$

O pertencimento elíptico de Nietzsche, em vida e postumamente, à virada entre os séculos XIX e XX pode ser avaliado, também, pelo modo como suas obras - e sua vida - receberam o tratamento dedicado aos décadents de então. Nele, lembra David Wachter, "a significação tradicionalmente pejorativa e contemporaneamente enaltecedora do conceito [de decadência] dialeticamente se misturam uma com a outra"49, algo que pode, sem muitos problemas, ser atribuído aos decadentistas em geral. Esse último confronto dialético de seus textos foi deixado de lado pelos que buscaram compreender seu nome, com ou sem razão, como uma ameaça. E isso se torna essencialmente problemático porque seu estatuto como autor não se apresentava, tanto para seus críticos quanto para seus propagandistas, de modo perfeitamente nítido: como ler Nietzsche? Como filósofo, filólogo, pensador, ideólogo, poeta? ${ }^{50}$ Essa pergunta angustiou uma geração inteira. Seria preciso esperar a sistemática e intermitente leitura de Heidegger, quer se concorde com ela ou não, para que Nietzsche viesse encontrar uma pátria um pouco mais circunscrita na filosofia. O que é,

47 Citado em ZEEB, T. "Die Wirkung Nietzsches auf die deutsche Gesellschaft der Jahrhundertwen im Spiegel der Tagespresse”. In: Nietzsche-Studien, Bd. 33, pp. 290-291.

48 Cf. MARTIN, N. “Fighting a Philosophy': The Figure of Nietzsche in British Propaganda of the First World War" In.: The Modern Language Review, Vol. 98, No. 2, pp. 367-380.

49 WACHTER, D. "Die Ambivalenz der décadence. Nietzsche, Bourget und Wagner". In: Focus on German Studies, n. 9, p. 149.

50 Sobre esse ponto, cf. A. "Nietzsche au miroir de la Belle Époque". In: CESSOLE, B. de \& CAUSSÉ, J. (org.), Nietzsche. 1892-1914, p. 3. 
certamente, algo importante para sua compreensão como Ja-Sager, como afirmador (cf. GM/GM, Segunda dissertação, 3, KSA 5.295). Mas, talvez, não o suficiente para pensá-lo como décadent.

\begin{abstract}
Nietzsche's appropriation of the term décadence - and its related ones - in texts written between 1887 and 1888 can point out not only his interest on a typical lexicon from the literature and physiology of belle époque, but also the way this vocabulary allowed him, at the same time, to face his own time and establish new writing strategies. Starting from the decadentist horizon and its narrative procedures between 1871 and 1914, this paper intends to analyze the tensions involved in Nietzsche's inscription within the period that lap over from his last writings to his first reception.
\end{abstract}

Keywords: Nietzsche - decadence - belle époque

\title{
referências bibliográficas
}

1. ASCHEIM, S. E. The Nietzsche Legacy in Germany: 1890 -1990. Berkeley: University of California Press, 1990.

2. BAUDELAIRE, C. Oeuvres completes. Paris: Robert-Laffont, 1980.

3. BERNHEIMER, C. Decadent Subjects. The Idea of Decadence in Art, Literature, Philosophy, and Culture of the Fin de Siècle in Europe. Baltimore and London: The Johns Hopkins University Press, 2002.

4. BISHOP, P. (ed.) A companion to Freidrich Nietzsche: life and works. Rochester: Camden House, 2012.

5. BOURGET, P. Essais de psychologie contemporaine, 10 ème. éd. Paris: Alphone Lemerre, s./d.

6. BROBJER, Th. "Nietzsche's Reading and Private Library, 1885-1889". In: Journal of the History of Ideas, Vol. 58, No. 4, 1997.

7. CALINESCU, M. Five Faces of Modernity: Modernism, Avant-Garde, Decadence, Kitsch and Postmodernism. Indiana: Duke University Press, 1987.

8. CRAWFORD, C. To Nietzsche: Dionysus, I love you! Ariadne, New York: State University of New York, 1995.

9. DELEUZE, G. Proust et les signes, 2ème. éd. Paris: PUF, 1998.

10. DIETHE, C. Historical dictionary of Nietzscheanism, $2^{\text {nd }}$. ed. Maryland: Scarecrow Press, 2007.

Cad. Nietzsche, São Paulo, n. 33, p. 245-272, 2013. | 269 
Lemos, F.

11. Nietzsche's Sister and The Will to Power: A Biography of Elisabeth FörsterNietzsche. Illinois: University of Illinois Press, 2003.

12. FINN, M. R. Proust, the Body and Literary Form, Cambridge: Cambrisge University Press, 2004.

13. GASCHÉ, R. “Autobiography as Gestalt: Nietzsche's Ecce Homo". In: boundary 2, Vol. 9, No. 3, 1981.

14. HILLEBRAND, B. (Hrsg.) Nietzsche und die deutsche Literatur, Bd. 1. München und Tübingen: Niemeyer, 1978.

15. HUNEKER, J. Egoists, a book of Supermen - Stendhal, Baudelaire, Flaubert, Anatole France, Huysmans, Barrès, Nietzsche, Blake, Ibsen, Stirner, and Ernest Hello. New York: Charles Scribner's Sons, 1909.

16. HUYSMANS, J.-K. A rebours/ Le drageoir aux épices. Paris: Christian Bourgeois, 1975.

17. JANZ, C. P. Friedrich Nietzsche. Biographie, 2. Aufl., München: Hanser, 1993.

18. JUIN, H. "Préface". In: HUYSMANS, J.-K. A rebours/ Le drageoir aux épices, Paris: Christian Bourgeois, 1975.

19. KLOSSOWSKI, P. Nietzsche et le cercle vicieux. Paris: Mercure de France, 1978.

20. KRUMMEL, R. F. Nietzsche und der deutsche Geist, Bd. 1. Berlin: de Gruyter, 1998.

21. LEMOS, F. "Nietzsche e a construção messiânica do wagnerianismo". In: TRANS/ FORM/AÇ̃̃ $O$, vol. 33, n.2, 2010.

22. MALLARMÉ, S. Oeuvres complètes, Paris: Gallimard, 1945.

23. MARTIN, N. “'Fighting a Philosophy': The Figure of Nietzsche in British Propaganda of the First World War". In: The Modern Language Review, Vol. 98, No. 2, 2003.

24. MAUPASSANT, G. de "Une femme". In: Chroniques. Paris: 10/18, 1993, t.2.

25. MOORE, G. Nietzsche, biology and metaphor. Cambridge: Cambridge University Press, 2002.

26. MÜLLER-LAUTER, W. "Décadence artística enquanto décadence fisiológica. A propósito da crítica tardia de Friedrich Nietzsche a Richard Wagner". Trad. Scarlett Marton. In: Cadernos Nietzsche, n. 6, 1999.

27. NICHOLLS, R. A. "Beginnings of the Nietzsche Vogue in Germany". In: Modern Philology, Vol. 56, No. 1, 1958.

28. NIETZSCHE, F. Sämtliche Briefe. Kristische Studienausgabe in 8 Bänden, hrsg. von Giorgio Colli und Mazzino Montinari, Munchen, Berlin und New York: Deutscher Taschenbuch Verlag und Walter de Gruyter, 1986.

29. . Sämtliche Werke. Kristische Studienausgabe in 15 Bänden. Hrsg. von

Giorgio Colli und Mazzino Montinari. Berlin; New York: Deutscher Taschenbuch Verlag und Walter de Gruyter, 1980.

30. NORDAU, M. Entartung, 2. Bd, 2. Aufl. Berlin: Carl Duncker, 1898.

270 | Cad. Nietzsche, São Paulo, n. 33, p. 245-272, 2013. 
31. PETERS, H. F. Nietzsche et sa soeur Elisabeth. Paris: Mercure de France, 1978.

32. PHILONENKO, A., "Nietzsche au miroir de la Belle Époque". In: CESSOLE, B. de \& CAUSSÉ, J. (org.) Nietzsche. 1892-1914. Paris: Maisonneuvre et Larose/ Éditions des Deux Mondes, 1997.

33. PROUST, M. À la rechereche du temps perdu, Paris: Gallimard, 1999.

34. RIMBAUD, A. Poésies. Une saison em enfer. Illuminations. Paris: Gallimard, 1973.

35. SICARD, M. "La femme hystérique: émergence d'une representation". In: Communication et languages, n. 127, 2001.

36. ___ “_Responda, cadáver': o discurso da crise na poseia moderna”. In: Alea, vol. 9, n. 2, 2007.

37. SILVERMAN, H. J. "The Autobiographical Textuality of Nietzsche's Ecce Homo". In: boundary 2, Vol. 9, No. 3, 1981.

38. WACHTER, D. "Die Ambivalenz der décadence. Nietzsche, Bourget und Wagner". In: Focus on German Studies, n. 9, 2002.

39. WEIR, D. Decadence and the making of Modernism. Massachusetts: University of Massachusetts Press, 1995.

40. ZEEB, T. "Die Wirkung Nietzsches auf die deutsche Gesellschaft der Jahrhundertwen im Spiegel der Tagespresse". In: Nietzsche-Studien, Bd. 33, 2004.

Artigo recebido para publicação em 11/05/2013.

Artigo aceito para publicação em 20/06/2013. 
